University of Wollongong

Research Online

Faculty of Engineering and Information

Faculty of Engineering and Information

Sciences - Papers: Part A

Sciences

$1-1-2012$

\title{
Optimization of welding parameters for repairing NiAl bronze components
}

\author{
Huijun Li \\ University of Wollongong, huijun@uow.edu.au \\ Daniel Grudgings \\ University Of Wollongong \\ Nathan P. Larkin \\ University of Wollongong, nlarkin@uow.edu.au \\ John Norrish \\ University of Wollongong, johnn@uow.edu.au \\ Mark Callaghan \\ University Of Wollongong, mcallagh@uow.edu.au
}

See next page for additional authors

Follow this and additional works at: https://ro.uow.edu.au/eispapers

Part of the Engineering Commons, and the Science and Technology Studies Commons

Research Online is the open access institutional repository for the University of Wollongong. For further information contact the UOW Library: research-pubs@uow.edu.au 


\title{
Optimization of welding parameters for repairing NiAl bronze components
}

\begin{abstract}
The objective of this study is to determine an optimal welding procedure that can be implemented to repair damaged Nickel Aluminium Bronze (NAB) components. NAB is commonly used in marine applications where components are subject to a constant corrosive environment and high stresses. Research into ideal NAB microstructure for a marine application, was performed in order to gain a baseline for experimental analysis of potential welding procedures. The results indicated that the welding repair can be performed with a wide range of heat input. The effect of post-weld heat treatment (PWHT) on the microstructure and mechanical properties in the heat affected zone (HAZ) and weld metal was also investigated in this research. The dominant microstructure in weld metal at as-welded condition is coarse Widmanstatten type structure with high hardness; post-weld heat treatment resulted in significant grain refinement and hardness reduction in weld metal.
\end{abstract}

\section{Keywords}

parameters, welding, components, optimization, bronze, nial, repairing

Disciplines

Engineering | Science and Technology Studies

\section{Publication Details}

Li, H., Grudgings, D., Larkin, N. P., Norrish, J., Callaghan, M. \& Kuzmikova, L. (2012). Optimization of welding parameters for repairing NiAl bronze components. Materials Science Forum, 706-709 2980-2985.

\section{Authors}

Huijun Li, Daniel Grudgings, Nathan P. Larkin, John Norrish, Mark Callaghan, and Lenka Kuzmikova 


\title{
Optimization of Welding Parameters for Repairing NiAl Bronze
}

\section{Components}

\author{
Huijun Li ${ }^{a}$, Daniel Grudgings ${ }^{b}$, Nathan Larkin ${ }^{c}$, John Norrish ${ }^{d}$, Mark Callaghan ${ }^{\mathrm{e}}$ \\ and Lenka Kuzmikova ${ }^{f}$
}

\author{
Defence Materials Technology Centre, University of Wollongong, Australia \\ ahuijun@uow.edu.au, ${ }^{\text {b }}$ dig699@uow.edu.au, ${ }^{\text {cnlarkin@uow.edu.au, }}$, dohnn@uow.edu.au, \\ e $\underline{\text { mcallagh@uow.edu.au, }} \underline{\text { Ik730@uow.edu.au }}$
}

Keywords: NAB, bronze, welding

\begin{abstract}
The objective of this study is to determine an optimal welding procedure that can be implemented to repair damaged Nickel Aluminium Bronze (NAB) components. NAB is commonly used in marine applications where components are subject to a constant corrosive environment and high stresses. Research into ideal NAB microstructure for a marine application, was performed in order to gain a baseline for experimental analysis of potential welding procedures. The results indicated that the welding repair can be performed with a wide range of heat input. The effect of post-weld heat treatment (PWHT) on the microstructure and mechanical properties in the heat affected zone (HAZ) and weld metal was also investigated in this research. The dominant microstructure in weld metal at aswelded condition is coarse Widmanstatten type structure with high hardness; post-weld heat treatment resulted in significant grain refinement and hardness reduction in weld metal.
\end{abstract}

\section{Introduction}

Nickel Aluminium Bronze (NAB) is a copper alloy with additions of nickel, aluminium and iron with a composition of typically $8-13 \mathrm{wt} \% \mathrm{Al}, 3-5 \mathrm{wt} \% \mathrm{Ni}, 3-5 \mathrm{wt} \% \mathrm{Fe}$ and $0-3 \mathrm{wt} \% \mathrm{Mn}$ additions, with copper making up the rest. It has strength similar to that of medium-carbon steel and superior corrosive resistance and erosion cavitation performance compared to most stainless steels. The formation of a tough aluminium oxide film $\left(\mathrm{Al}_{2} \mathrm{O}_{3}\right)$ gives $\mathrm{NAB}$ its excellent corrosion and erosion cavitation resistance. NAB's properties make it ideal for marine applications, and are largely used for impeller blades and other components in undersea and surface platforms [1-4].

Despite the excellent properties of NAB, components still suffer from wear, dealloying, corrosion, cavitation corrosion-erosion, and corrosion fatigue [5]. NAB components are expensive to replace so several methods are employed to extend their service life such as welding, metal cladding and laser surface finishing.

Although extensive research has been carried out on development of NAB cast microstructure, complete phase diagrams are yet to be constructed; one difficulty of welding NAB components is the lack of understanding of microstructural development in welds under different welding conditions. The phases of NAB give the material different properties. For example, the presence of alpha phase increases ductility but reduces hardness; beta phase increases hardness but can lead to dealloying and thus reduces corrosion resistance properties. This investigation reports on the effect welding parameters, 
such as current, voltage, wire feed rate and travel speed, on the microstructure of the weld bead and heat affected zone (HAZ).

\section{Experimental procedures}

The NAB material used for this research was cast slabs; the chemical composition is listed in Table 1.

Table 1 Alloy chemical composition (wt $\%)$

\begin{tabular}{|c|c|c|c|c|c|c|c|c|c|c|}
\hline $\mathrm{Zn}$ & $\mathrm{Pb}$ & $\mathrm{Sn}$ & $\mathrm{Mn}$ & $\mathrm{Fe}$ & $\mathrm{Ni}$ & $\mathrm{Si}$ & $\mathrm{Mg}$ & $\mathrm{Cr}$ & $\mathrm{Al}$ & $\mathrm{Cu}$ \\
\hline 0.02 & $<0.01$ & 0.02 & 1.1 & 4.4 & 5.2 & 0.07 & $<0.01$ & $<0.01$ & 8.8 & $\mathrm{Rem}$ \\
\hline
\end{tabular}

The welding wire was $1.2 \mathrm{~mm}$ AWSERCuNiAl solid wire manufactured by Oxford Alloys, the typical chemical analysis of this wire is shown in Table 2. The wire is recommended to weld cast and wrought nickel-alunimium bronze.

Table 2 Typical chemical analysis of welding wire (wt $\%)$

\begin{tabular}{|c|c|c|c|c|c|c|c|c|}
\hline $\mathrm{Cu}+\mathrm{Ag}$ & $\mathrm{Al}$ & $\mathrm{Fe}$ & $\mathrm{Ni}+\mathrm{Co}$ & $\mathrm{Mn}$ & $\mathrm{Si}$ & $\mathrm{Zn}$ & $\mathrm{Pb}$ & OET \\
\hline $\mathrm{Rem}$ & $8.5-9.5$ & $3-5$ & $4-5.5$ & $0.6-3.5$ & $0.1 \max$ & $0.1 \max$ & $0.02 \max$ & $0.5 \max$ \\
\hline
\end{tabular}

The welding was conducted using gas metal arc welding (GMAW) process shielded with 100\% argon gas; the welding parameters are listed in Table 3. Pre-heat temperature was between $50-90{ }^{\circ} \mathrm{C}$, the inter-pass temperature was controlled below $200{ }^{\circ} \mathrm{C}$. The post-weld heat treatment was conducted at $675^{\circ} \mathrm{C}$ for 6 hours in a furnace and then left to air cool.

Optical microscopy (OM) involved standard sample preparation methods. Samples were etched in a 0.05 mol solution of ferric chloride for 30 seconds. Micro hardness testing was performed on all samples. Readings were taken in the parent metal, HAZ and weld bead. Five readings were taken in each section.

\section{Results and Discussion}

The microstructure of parent metal is presented in Figure 1a, where the alpha phase was observed to be the predominant phase. It is a copper rich phase and is least likely to corrode. The KI phase are identified as the large globular/rosettes, $\kappa_{I I}$ are the dendritic rosettes; both these phases have the same composition, an iron rich aluminide, $\mathrm{Fe}_{3} \mathrm{Al}$, and are therefore often regarded as the same phase.

$\kappa_{\text {III }}$ phase are the lamellar, eutectoids in between the alpha phases and consist of a Nickel Aluminide, NiAl. The lamellar nature of the $\kappa_{\text {III }}$ can be clearly seen in Figure 1b. It is the lamellar or continuous nature of the $\kappa_{\text {III }}$ phase which gives rise to a large proportion of closely adjacent cathodic and anodic regions, resulting in a series of micro galvanic cells which accelerate corrosion in these regions. KIV phases are spec-like, scattered throughout the alpha phase with an iron aluminide composition, $\mathrm{Fe}_{3} \mathrm{Al}$, these do not pose many problems due to their fine, non-continuous characteristic. 
Table 3 Welding parameters

\begin{tabular}{|c|l|c|c|c|c|}
\hline Test No & & Current (A) & Voltage (V) & $\begin{array}{l}\text { Wire feed } \\
(\mathrm{m} / \mathrm{min})\end{array}$ & $\begin{array}{l}\text { Travel speed } \\
(\mathrm{mm} / \mathrm{min})\end{array}$ \\
\hline 1 & Low heat input & 155 & 16.5 & 5.5 & 300 \\
\hline 2 & Low heat input & 180 & 17 & 6.3 & 300 \\
\hline 3 & Medium heat input & 175 & 25 & 5.4 & 300 \\
\hline 4 & Medium heat input & 175 & 25 & 5.4 & 400 \\
\hline 5 & Medium heat input & 175 & 25 & 5.4 & 500 \\
\hline 6 & High heat input & 210 & 25 & 6.3 & 300 \\
\hline 7 & High heat input & 210 & 25 & 6.3 & 500 \\
\hline 8 & High heat input & 210 & 25 & 6.3 & 600 \\
\hline 9 & High heat input & 210 & 25 & 7 & 300 \\
\hline 10 & High heat input & 230 & 25 & 4.6 & 300 \\
\hline 11 & Dip transfer & 150 & 20 & 4.6 & 300 \\
\hline 12 & Cold metal transfer & 100 & 10.5 & 14 & 300 \\
\hline 13 & Cold metal transfer & 150 & 20 & & 300 \\
\hline 14 & Cold metal transfer & 200 & & & \\
\hline
\end{tabular}

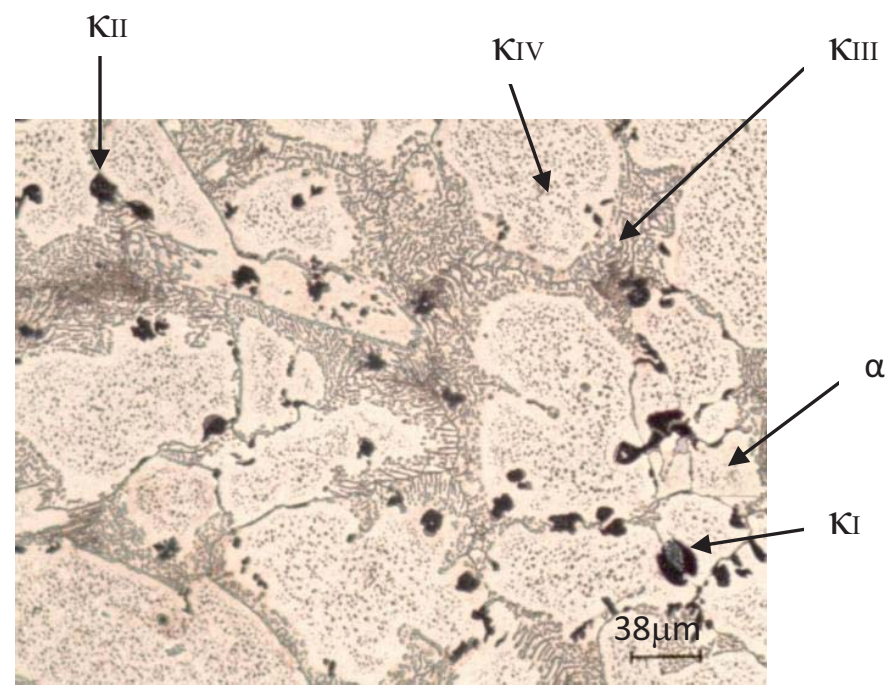

(a)

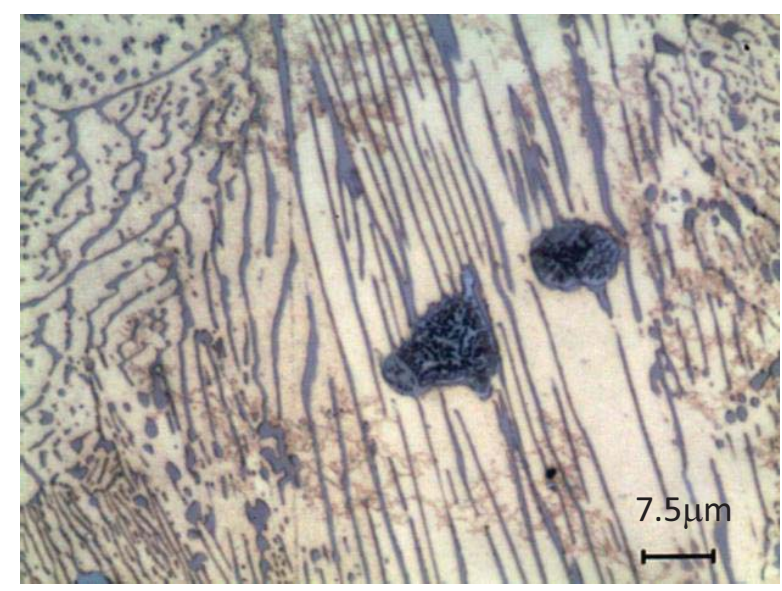

(b)

Figure 1 Typical parent metal microstructure 
Most welding procedures produced sound welds. The width of HAZ is very narrow $(<1 \mathrm{~mm})$ for all welding parameters. The microstructure underwent significant changes in the HAZ. A transformation of eutectic structure to martensitic occurred, in particular in areas close to the fusion line. The peak temperature in this area was above the eutectic point forming beta phase. This was retained with rapid cooling resulting in a martensitic structure (Figure 2). The changing temperature gradient with distance to the fusion line led to regions of a partially transformed eutectic structure (Figure $2 \mathrm{~b}$ ). The martensitic structure is harder than the alpha phase but also more brittle and susceptible to corrosion, making it undesirable.

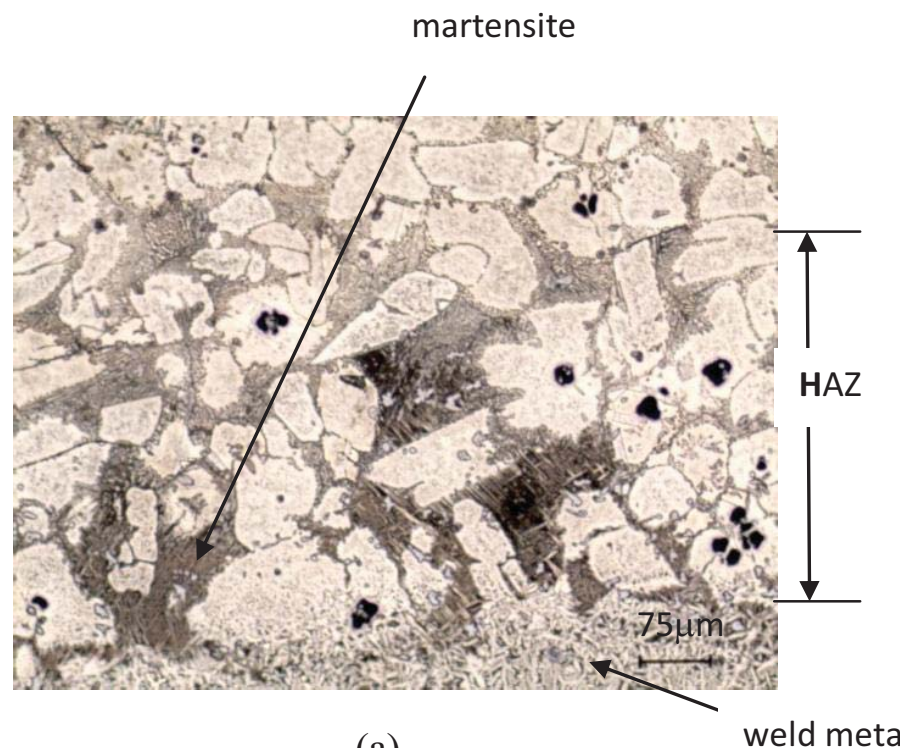

(a)

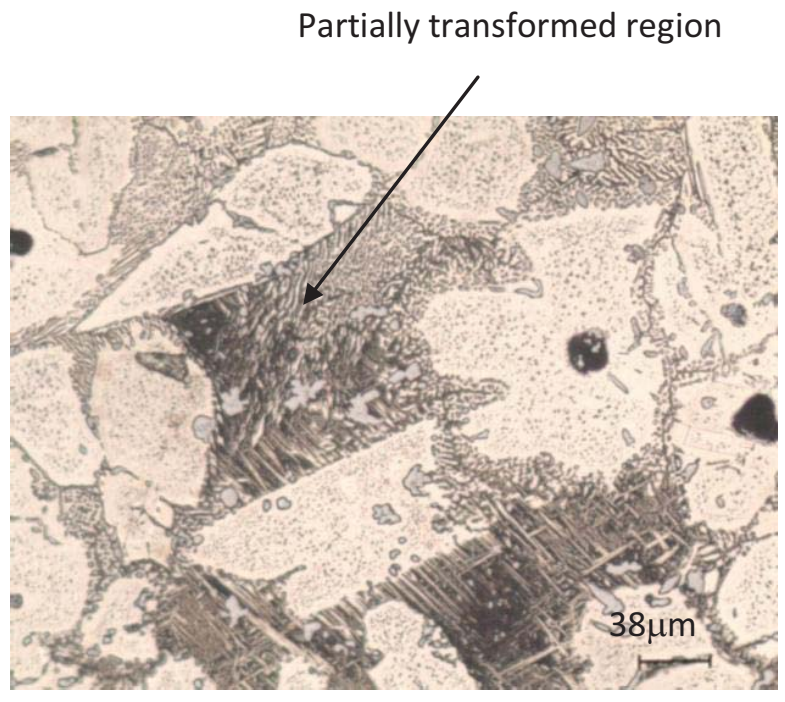

(b)

Figure 2 Typical HAZ microstructure

Figure 3 shows the microstructure of an as-deposited weld bead, it contains predominantly Widmanstätten alpha and very fine martensite (dark areas). It was fairly fine and uniform.

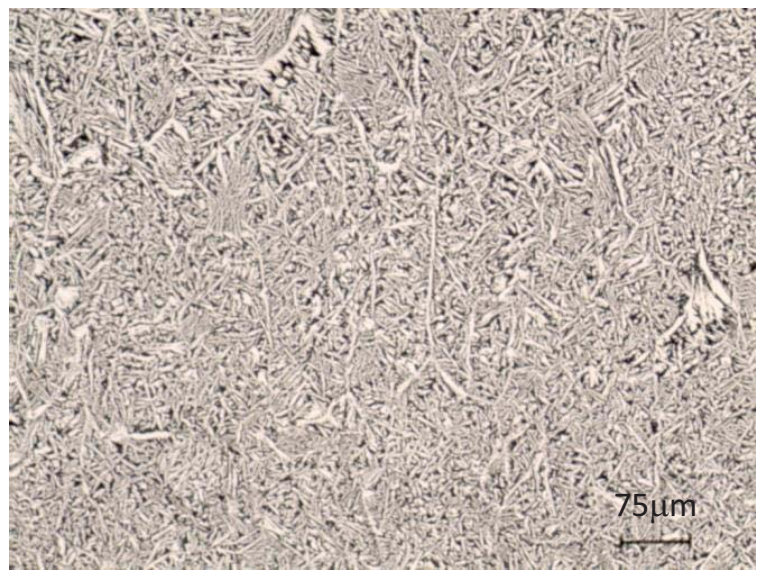

(a)

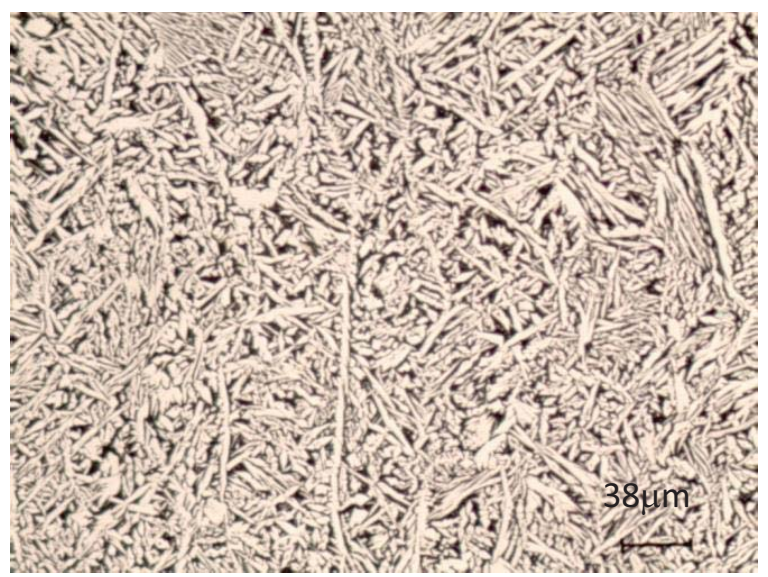

(b)

Figure 3 Typical Widmanstätten structure of AS deposited weld bead 
Post weld heat treatment (PWHT) relieves residual stresses and homogenises the microstructure. The samples were heated to $675^{\circ} \mathrm{C}$ for 6 hours. The parent metal contained stable casting structure; therefore little to no change occurred with the PWHT. The HAZ and weld bead, where martensite was present, was refined. The HAZ retained the large sections of alpha phase, however closer to the fusion line appeared partially decomposed, also the martensite was replaced with a fine grain alpha phase and kappa precipitates (Figure 4a).

Weld bead structures have a structure with Widmanstätten alpha and small amount of martensite, PWHT decomposed these, leaving a fine, homogenised microstructure of alpha phase and kappa precipitate (Figure 4b). The refining that occurred in both the HAZ and the weld metal was favourable. A fine microstructure provides additional strength to the material and improved corrosion resistance.

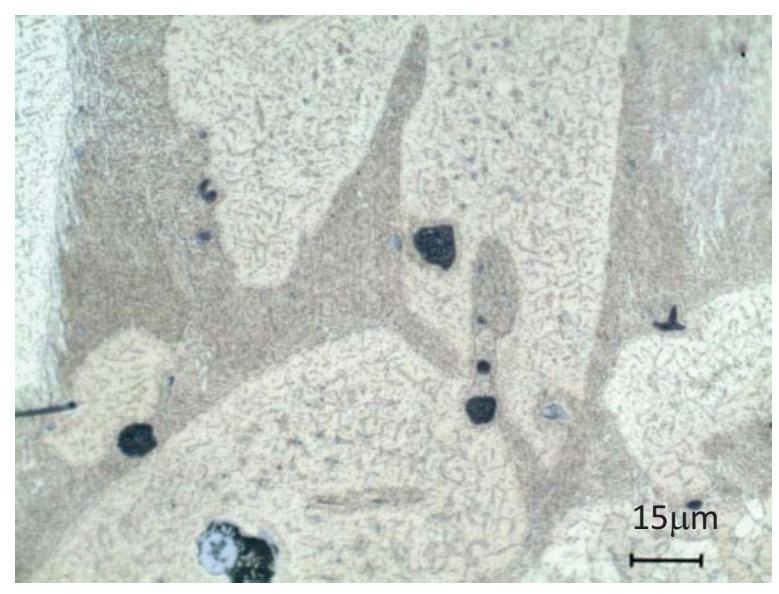

(a)

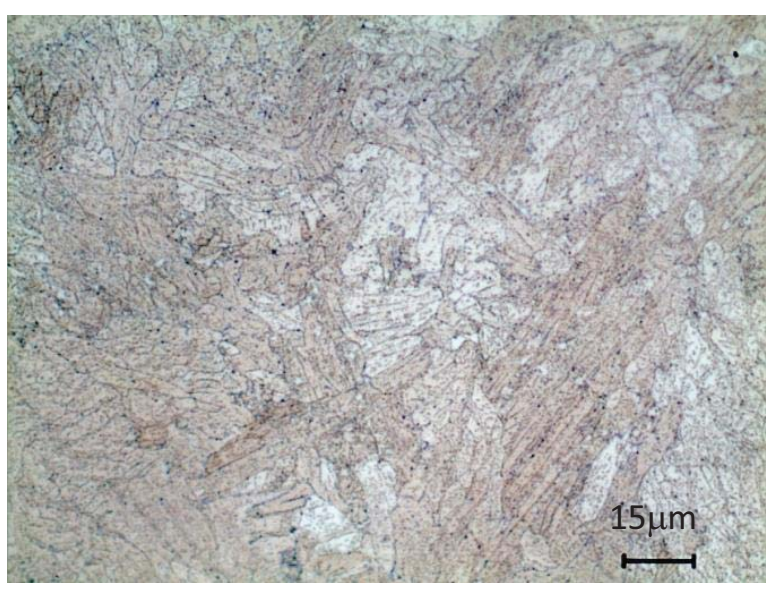

(b)

Figure 4 Typical microstructure of PWHT, (a) HAZ, (b) Weld metal

Micro hardness testing was performed to understand the effect of welding and PWHT on the hardness of the samples. Readings were taken for the parent metal, HAZ and weld metal. The parent metal showed little variation in readings. This is expected due to the consistent microstructure of the parent metal. The HAZ in samples that did not undergo PWHT however showed large variations of up to $180 \mathrm{HV}$. This was attributed to the presence of large sections of martensite (hard) and alpha phase (soft). The weld bead had a fairly fine grain leading to only small disparities between readings.

The effects of welding and PWHT can be seen from the hardness results (Figure 5). The martensite in the HAZ and weld bead in samples without PWHT, significantly increased the hardness of those sections, PWHT decomposed this but the newly refined microstructure was still harder than the original parent metal.

\section{Conclusions}

In summary, welding repair of NAB can be conducted with a wide range of welding parameters; the variation of microstructure and hardness among all welds was insignificant. Post-weld heat treatment refined the microstructure in welds and lowered their hardness. 


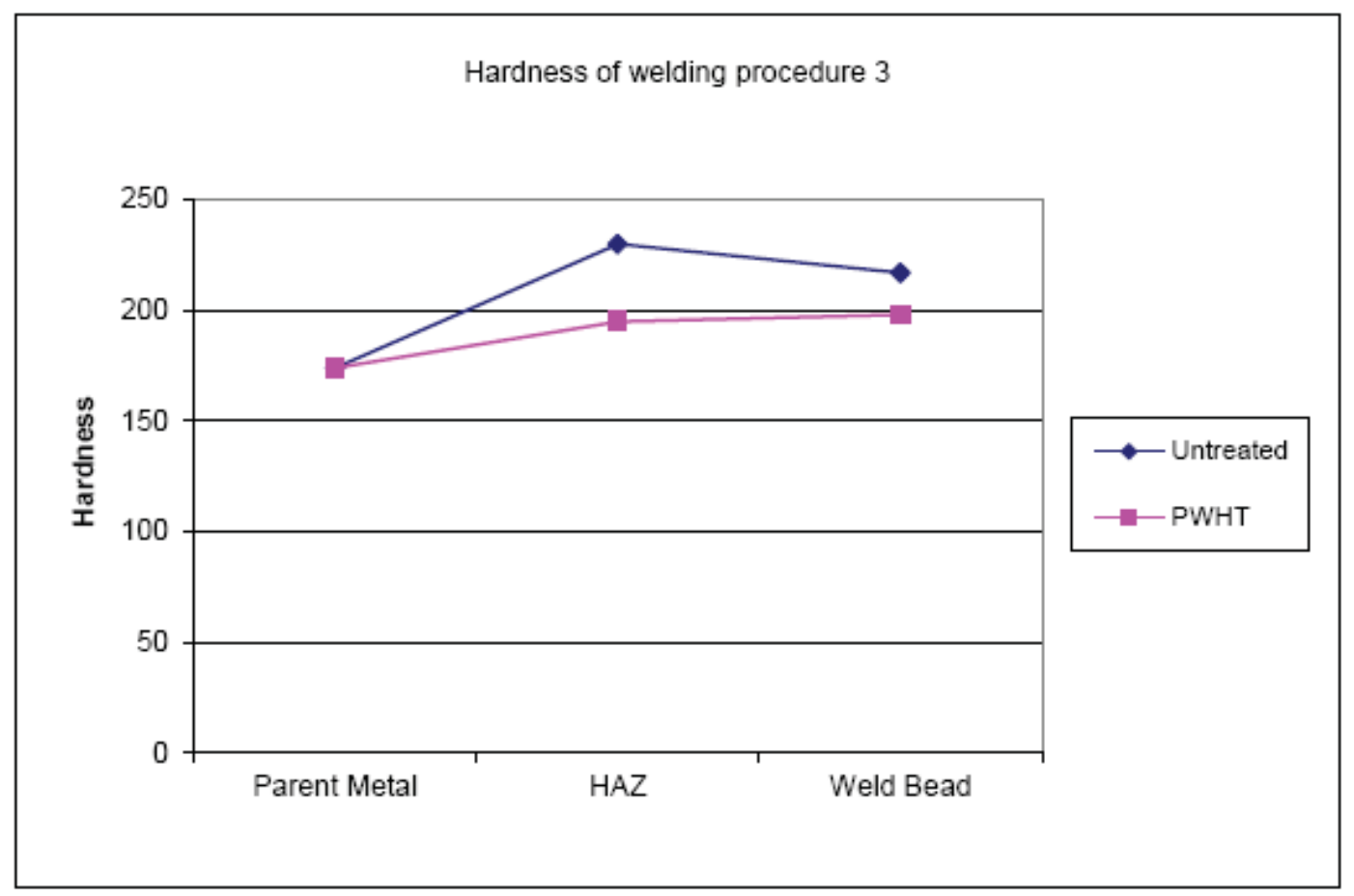

Figure 5 Typical graph of hardness results

\section{References}

[1] Ministry of Defence, (2000), "Defence Standard 02-771 (NES 771): Requirements, Procedure and Inspection for Weld Repair of Copper Alloy Nickel Allow Castings".

[2] Ministry of Defence, (2004), "Defence Standard 02-747 (NES 747): Requirements for Nickel Aluminium Bronze Castings and Ingots".

[3] A. Al-Hashem and W. Riad, "The role of microstructure of nickel-aluminium-bronze alloy on its cavitation behaviour in natural seawater", Matrials Characterisation, (2002), Volume 48, p. 37.

[4] F. Hasan, A. Jahanafrooz, G. W. Lorimer and N. Ridley, "The morphology, crystallography, and chemistry of phases in as-cast nickel-aluminum bronze", Metallurgical and Materials Transactions A, (1981), Volume 13, Issue 8, p. 1337.

[5] A. M. Olszewski, "Dealloying of a Nickel-Aluminium Bronze Impeller", Journal of Failure Analysis and Prevention, (2008), Volume 8, Number 6, p.505.

\section{Acknowledgement}

This work was mainly supported by the Defence Materials Technology Centre (DMTC), which was established and is supported by the Australian Government's Defence Future Capability Technology Centre (DFCTC) initiative. 